\title{
Article \\ Hemodynamic Response to Three Types of Urban Spaces before and after Lockdown during the COVID-19 Pandemic
}

\author{
Agnieszka Olszewska-Guizzo ${ }^{1,2, *(\mathbb{D})}$, Ayako Mukoyama ${ }^{3}$, Sho Naganawa ${ }^{3}$, Ippeita Dan ${ }^{3}$, Syeda Fabeha Husain ${ }^{4}$, \\ Cyrus S. Ho ${ }^{4}\left(\mathbb{D}\right.$ and Roger Ho ${ }^{1,4}$ \\ 1 Institute for Health Innovation \& Technology (iHealthtech) MD6, 14 Medical Drive, \#14-01, \\ Singapore 117599, Singapore; pcmrhcm@nus.edu.sg \\ 2 NeuroLandscape Foundation, Suwalska 8/78, 03-252 Warsaw, Poland \\ 3 Applied Cognitive Neuroscience Laboratory, Chuo University, 1-13-27 Kasuga, Bunkyo-ku, \\ Tokyo 112-8551, Japan; a15.whyr@g.chuo-u.ac.jp (A.M.); a15.tg3y@g.chuo-u.ac.jp (S.N.); dan@brain-lab.jp (I.D.) \\ 4 Department of Psychological Medicine, Yong Loo Lin School of Medicine, National University of Singapore, \\ NUHS Tower Block, Level 9, 1E Kent Ridge Road, Singapore 119228, Singapore; fabeha@nus.edu.sg (S.F.H.); \\ su_hui_ho@nuhs.edu.sg (C.S.H.) \\ * Correspondence: a.o.guizzo@neurolandscape.org or aga@nus.edu.sg; Tel.: +65-914-08-707
}

\section{check for}

updates

Citation: Olszewska-Guizzo, A.; Mukoyama, A.; Naganawa, S.; Dan, I.; Husain, S.F.; Ho, C.S.; Ho, R. Hemodynamic Response to Three Types of Urban Spaces before and after Lockdown during the COVID-19 Pandemic. Int. J. Environ. Res. Public Health 2021, 18, 6118. https://doi.org/10.3390/ ijerph18116118

Academic Editor: Paul B. Tchounwou

Received: 31 March 2021

Accepted: 3 June 2021

Published: 6 June 2021

Publisher's Note: MDPI stays neutral with regard to jurisdictional claims in published maps and institutional affiliations.

Copyright: (c) 2021 by the authors. Licensee MDPI, Basel, Switzerland. This article is an open access article distributed under the terms and conditions of the Creative Commons Attribution (CC BY) license (https:// creativecommons.org/licenses/by/ $4.0 /)$.

\begin{abstract}
Background: Prolonged lockdowns with stay-at-home orders have been introduced in many countries since the outbreak of the COVID-19 pandemic. They have caused a drastic change in the everyday lives of people living in urbanized areas, and are considered to contribute to a modified perception of the public space. As research related to the impact of COVID-19 restrictions on mental health and well-being emerges, the associated longitudinal changes of brain hemodynamics in healthy adults remain largely unknown. (2) Methods: this study examined the hemodynamic activation patterns of the prefrontal and occipital cortices of 12 participants ( 5 male, $\mathrm{M}_{\mathrm{age}}=47.80$, $\mathrm{SD}_{\text {age }}=17.79$, range 25 to 74 , and 7 female, $\mathrm{M}_{\mathrm{age}}=39.00, \mathrm{SD}_{\text {age }}=18.18$, range 21 to 65 ) passively viewing videos from three urban sites in Singapore (Urban Park, Neighborhood Landscape and City Center) at two different time points-T1, before the COVID-19 pandemic and T2, soon after the lockdown was over. (3) Results: We observed a significant and marginally significant decrease in average oxyhemoglobin $(\mathrm{Oxy}-\mathrm{Hb})$ over time for each of the visual conditions. For both green spaces (Urban Park and Neighborhood Landscape), the decrease was in the visual cortex, while for the City Center with no green elements, the marginal decrease was observed in the visual cortex and the frontal eye fields. (4) Conclusions: The results suggest that the COVID-19-related lockdown experienced by urban inhabitants may have contributed to decreased brain hemodynamics, which are further related to a heightened risk of mental health disorders, such as depression or a decline in cognitive functions. Moreover, the busy City Center scenes induced a hemodynamic pattern associated with stress and anxiety, while urban green spaces did not cause such an effect. Urban green scenes can be an important factor to offset the negative neuropsychological impact of busy urban environments post-pandemic.
\end{abstract}

Keywords: fNIRS; brain; lockdown; park; urban; environment; COVID-19

\section{Introduction}

Since the beginning of the COVID-19 pandemic in early 2020, we have observed everincreasing research highlighting its negative impact on the mental health and well-being of people worldwide. This is often attributed to economic uncertainty, fear of contracting the virus, losing a loved one, social isolation, or other drastic changes in everyday lifestyle during the prolonged stay-at-home orders introduced in many countries [1-3].

Less is known about the environmental aspects of stay-at-home orders and the longitudinal changes in brain functionality caused by the lockdowns in healthy urban populations. The city context is particularly interesting because infectious diseases are known to spread 
more easily in densely populated urban areas [4]. At the same time, there is less space available per capita in urban compared to rural areas, hence avoiding public places and crowds during a lockdown leads to significant changes in the typical sensory experience of a city dweller (for instance, more time spent indoors, more screen time, less time seeing other people). This, in turn, may have led to modulations in the visual and emotional processing of the urban environment.

Functional near-infrared spectroscopy (fNIRS) is a relatively recent brain-imaging technique providing a non-invasive and robust measurement of the light intensity changes (wavelengths between $650 \mathrm{~nm}$ and $1000 \mathrm{~nm}$ ) caused by the concentration of oxygenated hemoglobin (oxy- $\mathrm{Hb}$ ) and deoxygenated hemoglobin (deoxy-Hb) in the brain vessels [5]. The brain's neural activity in certain regions triggers an increase in blood flow and volume in those regions, which is disproportionately higher than the metabolic demand [6]. Even passive exposure to urban scenes requires cognitive resources to process sensory stimuli, which can be reflected as a brain activity pattern on the fNIRS scan. These patterns occur in certain regions of the brain cortex. For the scope of this study, the frontal and occipital regions are particularly important to focus on. The frontal region (or frontal lobe) is one of the most important neuroanatomical structures and plays an important role in emotional [7] and cognitive [8] task processing, among other executive functions. The occipital lobe, on the other hand, is commonly associated with visual processing and spatial orientation $[9,10]$.

Previous brain imaging research shows that the level of cognitive effort or attention pattern utilized to process different scenes can vary. More specifically, it has been shown that scenes of nature induce less strenuous, involuntary attention, [11,12] and less activity associated with stress and anxiety $[13,14]$ when compared to busy urban scenes (with noise, cars, buildings, and crowds). These findings support the Attention Restoration Theory (ART), according to which an exposure to nature has a soothing, balancing effect on emotions and can restore depleted attention, while also reducing mental fatigue [15-17]. Nevertheless, the brain hemodynamic patterns underlying exposure to urban and natural scenes in the context of a COVID-19-related lockdown remains unknown. Our parallel electroencephalography (EEG) study with a similar design confirmed the general decline in mood and approach-related motivation towards urban scenes after the lockdown when compared to before [18]. However, visual attention patterns were not tested in our EEG study.

To fill this gap in knowledge, the purpose of the current experiment is to explore the impact of the lockdown with stay-at-home orders on the hemodynamic, frontal, and occipital response of a healthy adult population at three urban sites in the highly urbanized country of Singapore, in a controlled, laboratory-based longitudinal study. We expect that the considerable change of lifestyle imposed by the lockdown contributed to general changes in the brain's hemodynamic patterns, which will manifest as modulations in the frontal and occipital regions of the brain. Given the previous findings in environmental neuroscience, we also expect to observe varying brain reactivity towards different types of urban spaces, with green spaces generating a more soothing effect on the brain as compared to urban scenes.

\section{Materials and Methods}

\subsection{Participants}

We recruited 25 right-handed, healthy subjects (11 male, $\mathrm{M}_{\mathrm{age}}=40.73, \mathrm{SD}_{\mathrm{age}}=18.27$, range 21 to 74 , and 14 female, $\mathrm{M}_{\mathrm{age}}=39.50, \mathrm{SD}_{\mathrm{age}}=17,94$, range 29 to 69) for two fNIRS scans based in the same laboratory room at the university premises. The first scan (T1) took place between the second quarter of 2019 and the first quarter of 2020. The last participant for T1 was accepted for a scan four days before the first COVID-19-related restrictions affecting public space were announced by the Singapore Ministry of Health (introducing body temperature screening at the entrance to selected public spaces) on 20 January 2020 [19]. The second scan (T2) took place between 2 and 30 June 2020-right after the 56-day-long 
lockdown in Singapore was over. None of the participants had any previous history of psychiatric, neurological, or chronic medical diseases. The study protocol was approved by the National University of Singapore's Ethics Committee (NUS-IRB_S-20-12).

\subsection{Study Protocol and Setup}

After signing the informed consent, participants had a portable fNIRS cap set on their head, followed by the light-blocking over-cap. They were then instructed to sit comfortably on the chair and passively watch the presentation of nine fixed-frame videos repeated three times, in a random order, displayed on a $108 \times 178 \mathrm{~cm}$ roll-up screen positioned about $200 \mathrm{~cm}$ in front of their eyes. There was a $60 \mathrm{~s}$ long resting state preceding the video presentations, where participants were looking at a gray, empty screen. Videos were $20 \mathrm{~s}$ long (passive task) with a $15 \mathrm{~s}$ pause in between, at which time a fixation cross was displayed on the screen (Figure 1). The videos were projected using the HD29 Darbee Optoma Home Theatre Full HD projector with 1080p $(1920 \times 1080)$ screen resolution. The natural sound, as recorded, was also played with the video using standard PC audio speakers placed near the projector, behind the participant's chair. During the experiment, a daylight-imitating lamp (with a light hue of $5500 \mathrm{~K}$ ) was turned on.

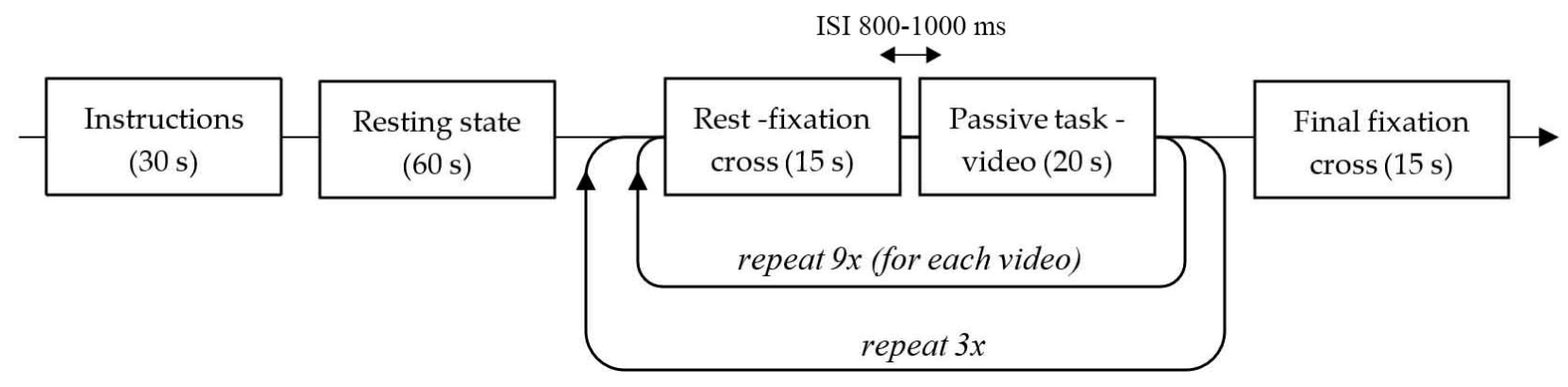

Figure 1. T1 and T2 brain imaging protocol.

\subsection{Stimuli}

Presentation of stimuli consisted of nine scenes captured at three public urban spaces in Singapore (Figure 2). Two of these locations were green spaces where no people were within view: Urban Park, where scenes included lush greenery settings, and the Neighborhood Landscape, which besides vegetation included more paved areas and residential buildings than the park. The third location, City Center, had negligible natural elements, plentiful views of buildings, infrastructure, people (without masks, as videos were filmed before the pandemic), and street traffic. All videos were recorded with a Sony ${ }^{\mathrm{TM}}$ HDR-TD30 camcorder with a frame size of $1920 \times 1080$ pixels, 50 frames per second, and 16:9 aspect ratio in TS(AVC)("** $\left.\mathrm{m} 2 \mathrm{ts}^{\prime \prime}\right)$ format, and were $20 \mathrm{~s}$ long. The video files were converted to MP4 format supported by presentation software (compression rate 50:1), using VideoProc 3.2 (Digiarty Software Inc.). All videos were comparable in terms of luminance ( $\mathrm{M}=124.0$, $\mathrm{SD}=7.1)$ and root-mean-square contrast $(\mathrm{M}=52.6, \mathrm{SD}=3.4)$, and were not processed further, so as to avoid low-level influence on attentional processing [20]. 


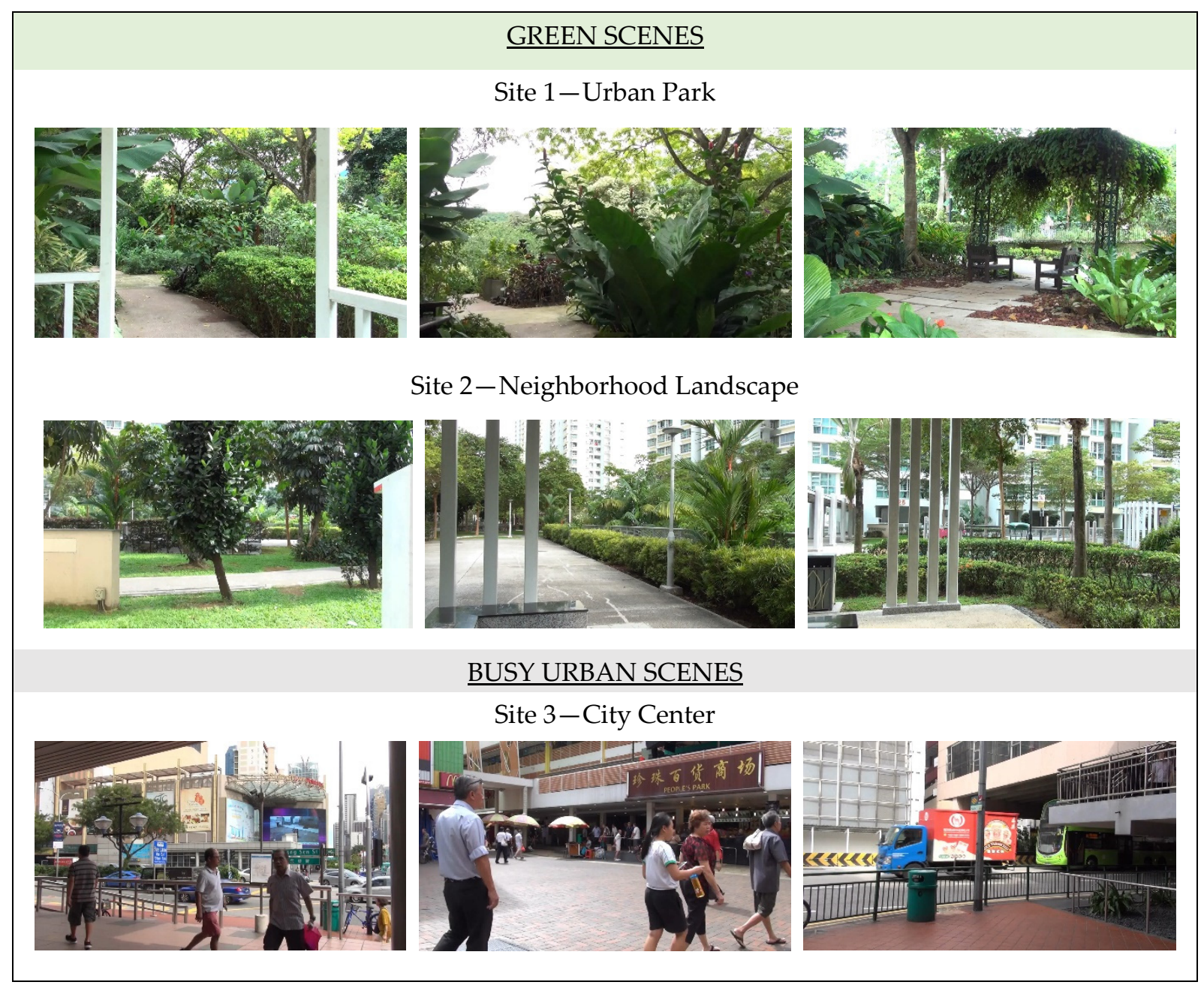

Figure 2. Photo snippets of the still-frame videos presented to participants.

\subsection{Measurement of Brain Activity}

Two portable NIRS SPORT devices by NIRx ${ }^{\circledR}$ (NIRx Medical Technologies, LLC, Berlin, Germany), with eight sources and eight detectors each, were combined in tandem mode onto a stretchable aniCAP (supplied by NIRx ${ }^{\circledR}$ ) according to a pre-set prefrontal-occipital montage (Figure 3). Cortical hemodynamics were measured with two wavelengths of nearinfrared light $(760$ and $850 \mathrm{~nm}$ ) and the sampling rate was set at $3.47 \mathrm{~Hz}$. Positional data of sources and detectors were obtained for two non-participants of fNIRS measurement (1 male, 1 female, both age 24 ) using a 3D digitizer supplied by NIRx ${ }^{\circledR}$.

For spatial profiling of fNIRS data, we adopted the probabilistic registration method [21-23] to register the data to the Montreal Neurological Institute's (MNI) (Montreal, QC, Canada) standard brain space. The macro-anatomical labeling was based on [24]. 

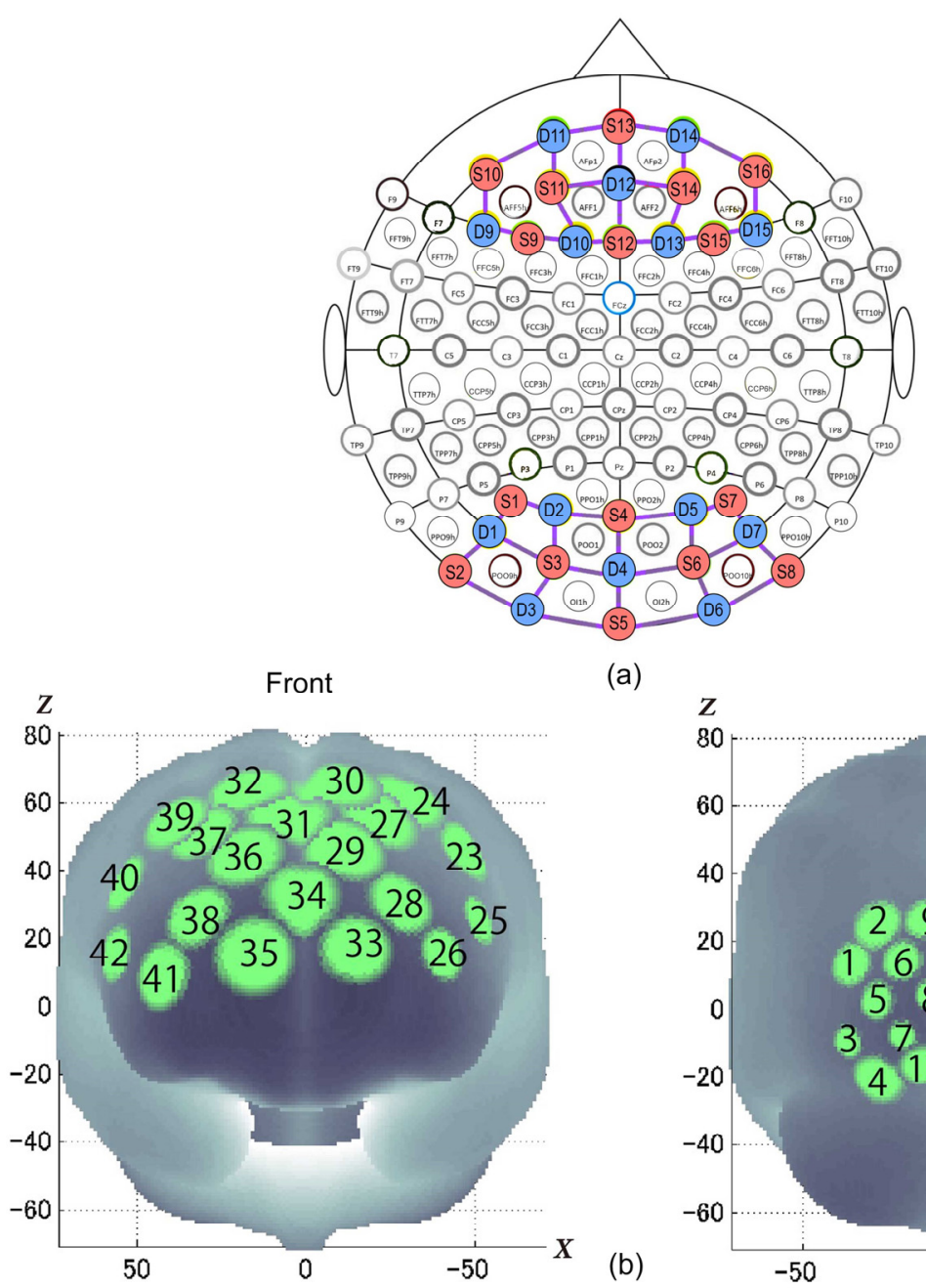

(a)

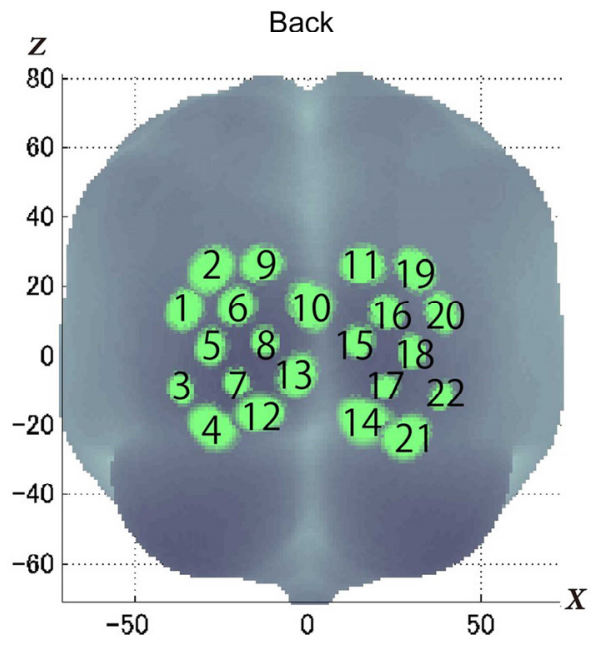

Figure 3. (a) Montage map with optodes placement (sources (S) in red and detectors (D) in blue) and (b) statistically estimated fNIRS channel locations on the brain for two students, their spatial variability (SDs radii of the light green circles) associated with the estimation exhibited in MNI space. Front and back head views.

\subsection{Data Processing and Analysis}

Signals reflecting the oxygenated hemoglobin $(\mathrm{oxy}-\mathrm{Hb})$ and deoxygenated hemoglobin $($ deoxy- $\mathrm{Hb})$ changes were calculated in units of millimolar-millimeter (mM-mm) using Homer 3 [25].

For the statistical analysis, the General Linear Model (GLM) method was used, which was optimized for fNIRS data to calculate beta values (response amplitudes) [26].

We analyzed changes in oxy- $\mathrm{Hb}$ signal because of its higher sensitivity to changes in cerebral blood flow than that of deoxy-Hb and total-Hb signals [27-29], its higher signal-tonoise ratio [28], and its higher retest reliability [30]. First, we preprocessed the individual time series data for the oxy- $\mathrm{Hb}$ of each channel. The channels with signal variation of $10 \%$ or less were considered defective measurements, and therefore excluded from the analysis. Second, we removed the influence of measurement noise, such as breathing and cardiac movement, from the remaining channels using the Wavelet-Minimum Description Length (Wavelet-MDL) detrending algorithm [31].

After preprocessing, we analyzed in Matlab 2007b with the tools from [26] using the adaptive GLM, and by regressing the data with a linear combination of explanatory variables, i.e., regressors and an error term. We generated the regressors (Equation (2)) by 
convolving the boxcar function $N\left(\tau_{p}, t\right)$ with the hemodynamic response function (HRF), shown in Equation (1) [32].

$$
\begin{gathered}
h h\left(\tau_{p}, t\right)=\frac{t^{\tau_{p}} e^{-t}}{\left(\tau_{p}\right) !}-\frac{t^{\tau_{p}+t_{d}} e^{-t}}{A\left(\tau_{p}+\tau_{d}\right) !} \\
f\left(\tau_{p}, t\right)=h\left(\tau_{p}, t\right) * N
\end{gathered}
$$

We set the first peak delay, $\tau_{p}$, at $6 \mathrm{~s}$ (which is a typical set in most fMRI studies), the second peak delay, $\tau_{d}$, at $16 \mathrm{~s}$ and $\mathrm{A}$-the amplitude ratio between the first and second peak-at 6 . The first and second derivatives were included in order to further remove the influence of noise on individual data. Regressors included were the rest-fixation cross (Rest) and the passive task-video (Stimuli) for each condition. The $\beta$ value is used as an estimate of the HRF prediction of the oxy- $\mathrm{Hb}$ signal. $\beta 1, \beta 4$ and $\beta 7$ are coefficients for the HRF of each condition. $\beta 2, \beta 5$ and $\beta 8$ are coefficients for first derivatives on the HRF of each condition. $\beta 3, \beta 6$ and $\beta 9$ are coefficients for second derivatives on the HRF of each condition. $\beta 10, \beta 11$ and $\beta 12$ are coefficients for the HRF and first and second derivatives of Rest. $\beta 13$ is a constant term. A total of thirteen $\beta$ values were calculated. An example of design matrix $X$ is shown in Figure 4.

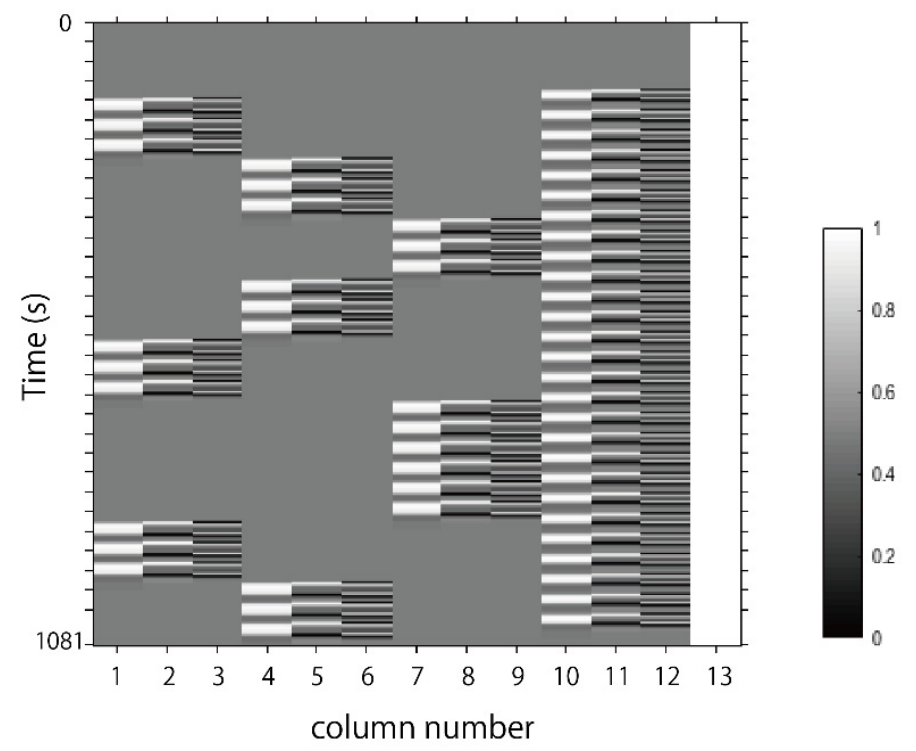

Figure 4. An example of design matrix $X$. The first peak delay was set as $\tau_{p}=6 \mathrm{~s}$ and "Time" indicates the row number of samples. The first to third columns indicate the canonical $\operatorname{HRF} f\left(\tau_{p}, t\right)$, the derivatives, and the second derivatives, respectively, for site 1 . The fourth to sixth columns indicate the canonical $\operatorname{HRF} f\left(\tau_{p}, t\right)$, the derivatives, and the second derivatives, respectively, for site 2 . The seventh to ninth columns indicate the canonical $\operatorname{HRF} f\left(\tau_{p}, t\right)$, the derivatives, and the second derivatives, respectively, for site 3 . The tenth to twelfth columns indicate the canonical $\operatorname{HRF} f\left(\tau_{p}, t\right)$, the derivatives, and the second derivatives, respectively, for Rest. The thirteenth column indicates the constant.

For each channel and each condition, the $\beta$-values obtained were subjected to group analyses. First, we screened for the channels that exhibited any possible lockdown-related change between the first and second scans (T1 and T2). Specifically, we calculated the contrasts between $\mathrm{T} 1$ and $\mathrm{T} 2$, and performed one-sample $t$-tests (two-tails) against zero. We set the statistical threshold at 0.05, with the Meff (Effective Multiplicity Correction Method) correction used for family-wise errors [33]. Next, we further analyzed the effects of the time of scans (before and after the lockdown, Tables 1 and 2, respectively) and sites (S1, S2, S3), with $2 \times 3$ repeated-measures analysis of variance (ANOVA) on the channels that exhibited possible hemodynamic changes according to the one-sample $t$-test described 
above. We corrected the $p$ value by Bonferroni method for family-wise errors. For reporting statistics, we used the 6th edition of the American Psychological Association's (APA) statistic standards [34], where $p<0.05$ is considered significant, and a $p$ value between 0.05 and 0.1 can be considered marginally significant, with the latter especially prevalent in the area of experimental psychology [35].

Table 1. The MNI coordinates of channel 9, 10, 19, 27 and the probability of the recorded data originating from the listed anatomical locations.

\begin{tabular}{|c|c|c|c|c|c|c|}
\hline Channel & $\mathbf{x}$ & $\mathbf{y}$ & $\mathbf{z}$ & SD & Anatomy & MAL(\%) \\
\hline \multirow[t]{2}{*}{9} & -13.3 & -100.0 & 26.3 & 7.2 & BA18-Visual Association Cortex (V2), left & 74.8 \\
\hline & & & & & BA17-Primary Visual Cortex (V1), left & 25.2 \\
\hline \multirow[t]{2}{*}{10} & 0.3 & -101.3 & 14.3 & 8.6 & BA17-Primary Visual Cortex (V1), left & 84.8 \\
\hline & & & & & BA18-Visual Association Cortex (V2), left & 15.2 \\
\hline \multirow[t]{2}{*}{19} & 30.7 & -94.0 & 24.7 & 7.7 & BA18-Visual Association Cortex (V2), right & 74.7 \\
\hline & & & & & BA19-Visual Association Cortex (V3), right & 25.3 \\
\hline \multirow[t]{2}{*}{27} & -21.3 & 36.3 & 55.3 & 13.6 & BA8-Frontal eye fields, left & 58.1 \\
\hline & & & & & BA9-Dorsolateral prefrontal cortex, left & 41.9 \\
\hline
\end{tabular}

SD indicates standard deviation in the spatial estimate. BA stands for Brodmann Area. MAL stands for macroanatomical probability. MAL is based on Roden and Brett (2000).

Table 2. Channels showing marginally significant and significant difference in oxy- $\mathrm{Hb}$ signals in contrast with baseline ("T2-T1").

\begin{tabular}{ccccccc}
\hline & Channel & Mean $(\mathbf{m M} \cdot \mathbf{m m})$ & SD & $t$ & $p$ & Sig \\
\hline Site 1 & 9 & -0.225 & 0.223 & -3.50 & 0.0471 & $*$ \\
Urban Park & 19 & -0.164 & 0.178 & -3.19 & 0.0814 & $t$ \\
\hline Site 2 & 9 & -0.286 & 0.287 & -3.44 & 0.0503 & $\dagger$ \\
Neighborhood Landscape & 19 & -0.207 & 0.223 & -3.22 & 0.0757 & + \\
\hline Site 3 & 10 & -0.365 & 0.388 & -3.26 & 0.0708 & + \\
City Center & 27 & -0.207 & 0.226 & -3.16 & 0.0843 & $t$ \\
\hline
\end{tabular}

Statistical significance is presented as follows: $+p<0.1 ;{ }^{*} p<0.05$. Abbreviations: SD, standard deviation; $t, t$ value; $p, p$ value; sig, statistical significance.

\section{Results}

Due to the data loss, caused by poor data quality due to thick hair and the contamination of the fNIRS signals by task-evoked physiological noise, only data from 12 out of the initial 25 participants ( 5 male, $\mathrm{M}_{\text {age }}=47.80 \mathrm{SD}_{\text {age }}=17.79$, range 25 to 74 , and 7 female, $\mathrm{M}_{\mathrm{age}}=39.00, \mathrm{SD}_{\mathrm{age}}=18.18$, range 21 to 65 ) were included. They were all Singapore residents with normal or corrected-to-normal vision; seven were Chinese, four were Indian, and one was of another ethnicity. They were mainly university-educated $(n=10)$, living in a five-person (four bedroom) household $(n=5)$, four-person (three bedroom) household $(n=3)$, or three-person (two bedroom) household $(n=3)$. One participant declared living alone in a one-bedroom apartment.

\section{fNIRS Results}

We analyzed the contrast between $\mathrm{T} 1$ and $\mathrm{T} 2$ to investigate any effects of the lockdown on oxy- $\mathrm{Hb}$ changes during the presentation of each scene. For site 1, we found a significant difference in the CH9 (one-sample $t$-test, $p<0.05$, Cohen's $\mathrm{d}=-1.01$, Tables 1 and 2 ) and a marginally significant difference in the $\mathrm{CH} 19$, but a moderate effect size was obtained (one-sample $t$-test, $p>0.05$, Cohen's $\mathrm{d}=-0.92$, Tables 1 and 2) with a Meff value of 9.41. For site 2, we found a marginally significant difference, but a moderate effect size was obtained in the CH9 (one-sample $t$-test, $p>0.05$, Cohen's $\mathrm{d}=-1.00$, Tables 1 and 2) and the CH19 (one-sample $t$-test, $p>0.05$, Cohen's $\mathrm{d}=-0.93$, Tables 1 and 2) with a Meff value of 9.22. For site 3, we found a marginally significant difference, but the moderate effect size was obtained in the CH10 (one-sample $t$-test, $p>0.05$, Cohen's $\mathrm{d}=-0.94$, Tables 1 and 2) and the CH27 (one-sample $t$-test, $p>0.05$, Cohen's $d=-0.91$, Table 1 ) with a Meff value of 9.34 . 
According to the initial screening results, we conducted the $2 \times 3$ repeated-measured ANOVA on $\mathrm{CH} 9, \mathrm{CH} 10, \mathrm{CH} 19$ and $\mathrm{CH} 27$. For $\mathrm{CH} 9$, the result showed a significant difference in the scan time factor $\left(\mathrm{F}(1,11)=12.546, p=0.019, \eta_{\mathrm{p}}{ }^{2}=0.533\right)$. We found no significant differences in the site factor $\left(\mathrm{F}(2,22)=2.624, p=0.380, \eta_{\mathrm{p}}{ }^{2}=0.193\right)$ or in the interaction effects $\left(F(2,22)=0.7329, p=1.968, \eta_{p}^{2}=0.062\right)$. For $\mathrm{CH} 10$, we found no significant differences in the scan time factor $\left(\mathrm{F}(1,11)=6.242, p=0.118, \eta_{\mathrm{p}}{ }^{2}=0.362\right)$, the site factor $\left(\mathrm{F}(2,22)=0.0396, p=3.845, \eta_{\mathrm{p}}{ }^{2}=0.004\right)$, or the interaction effects $(\mathrm{F}(2,22)=1.222, p=1.256$, $\left.\eta_{\mathrm{p}}{ }^{2}=0.100\right)$. For $\mathrm{CH} 19$, the result showed a significant difference in the scan time factor $\left(\mathrm{F}(1,11)=11.511, p=0.024, \eta_{\mathrm{p}}{ }^{2}=0.511\right)$. Still, we found no significant differences in the site factor $\left(\mathrm{F}(2,22)=0.703, p=2.024, \eta_{\mathrm{p}}{ }^{2}=0.060\right)$ or the interaction effects $(\mathrm{F}(2,22)=0.4978$, $\left.p=2.458, \eta_{\mathrm{p}}^{2}=0.043\right)$. For $\mathrm{CH} 27$, we found no significant differences in the scan time factor $\left(\mathrm{F}(1,11)=6.670, p=0.102, \eta_{\mathrm{p}}^{2}=0.378\right)$, the site factor $\left(\mathrm{F}(2,22)=2.191, p=0.542, \eta_{\mathrm{p}}{ }^{2}=0.166\right)$, or the interaction effects $\left(F(2,22)=0.999, p=1.538, \eta_{p}^{2}=0.083\right)$. Accordingly, we estimated macro-anatomical labels (Table 1) using Brodmann's atlas [24].

\section{Discussion}

The objective of this study was to explore the impact of the COVID-19-related lockdown on the brain hemodynamics during a passive task exposure to three urban scenes in Singapore: two urban green spaces (Urban Park and Neighborhood Landscape), and one busy urban core (City Center) with negligible greenery. We compared levels of blood oxidation $($ oxy $-\mathrm{Hb})$ in the frontal and occipital cortex of the same group of 12 individuals before and after the lockdown.

The results indicated the differences in brain hemodynamics based on the different content of the videos. Notably, videos of urban green spaces (Urban Park and Neighborhood Landscape) triggered a decrease in brain hemodynamics over time in symmetrically positioned channels: $\mathrm{CH} 9$ on the left, and $\mathrm{CH} 19$ on the right occipital lobe (with $\mathrm{CH} 19$ showing marginal statistical significance). At the same time, in the City Center condition, we observed a marginally significant decrease in occipital hemodynamics over time, but in the midline occipital region $\mathrm{CH} 10$ (Table 2). The difference in symmetry in urban versus green views can be explained by the "contralateral effect", according to which when visual attention is directed to the right hemifield, attentional modulations are found in the left occipital lobe, and, conversely, visual attention to the left hemifield causes decreased activity in the right visual cortex $[9,10]$. Visual attention being evenly distributed around the hemifield while observing green spaces suggests global visual processing-seeing the space as a whole,- -while, in the case of the City Center, attention could be local-fragmented and focused on processing multiple scattered elements (people, cars, buildings, signage, etc.) [36]. This difference in processing urban and green scenes was demonstrated in previous EEG studies [37] and is related to the restorative and balancing effect that nature scenes have on the mind, according to the Attention Restoration Theory (ART) $[15,17]$.

In our experiment, the City Center was the only condition triggering a marginally significant change in the frontal cortex over time. After the lockdown, participants viewing the busy urban scene had significantly lower levels of oxy- $\mathrm{Hb}$ in $\mathrm{CH} 27$ positioned on the left superior frontal cortex. At the same time, no significant changes in the frontal lobes between $\mathrm{T} 1$ and $\mathrm{T} 2$ were detected in the green space conditions. This effect coupled with the local fragmented visual attention may suggest more psychological strain while exposed to busy urban scenes as compared to the green space scenes. The potential mechanism of this may be related to aversive attitudes towards busy, crowded public places that emerged during the pandemic, especially since pedestrians present on the City Center videos were not wearing the face masks-a previous study has highlighted the association between not wearing masks and increased symptoms of post-traumatic stress disorder during the COVID-19 pandemic [38]. Additionally, videos with urban nature did not include any people or reminders of the pandemic, which could have had a calming effect on participants. 
Furthermore, the ANOVA results show that the $\mathrm{CH} 9$ and $\mathrm{CH} 19$ activation was significantly different between scan times (T1-T2), and that this difference is independent of the site factor. This suggests that the effect of the lockdown on the brain hemodynamics was not region-specific, but rather it holistically affected the brain's reactivity to all sceneries. We observed that the levels of oxy- $\mathrm{Hb}$ in these channels decreased over time (Table 2). Decreased brain hemodynamics are commonly associated with depressive symptoms [39] and aging of the brain [40,41]. The biological mechanisms of these phenomena are not fully understood, but some studies have suggested that depression is linked with the neurons and glial cells losing some of their functions, thereby causing lower levels of regional brain electrical activity, which in turn lead to decreased levels of oxy-Hb [42]. On an emotional level, depression is often characterized by emotional withdrawal or an aversive attitude towards the external stimuli [43]. Aging research, on the other hand, shows that with years passing by, the neural volume and activity tends to decrease [44], which may in turn be linked to a decrease in brain oxy- $\mathrm{Hb}$ in certain brain regions. The depressive symptoms occurring post-lockdown seem to be supported by previous behavioral studies [1,2] as well as longitudinal EEG experiments [18]; people experiencing distress, uncertainty, social isolation and stimuli deprivation may have developed depressive symptoms over the lockdown period. It is also plausible that some slower neural reactivity to visual stimuli (typical in older age participants) may have occurred as a result of a prolonged change of everyday routine and limited sensory stimulations. In this regard, studies have highlighted an alarming increase in the use of digital devices during the pandemic among youths and adults $[45,46]$. Simultaneously, there has been a decrease in physical activity and time spent outdoors $[47,48]$, which are considered as opportunities to relax eye strain by looking at more distant natural objects $[49,50]$. This may be an important explanation for the general changes in visual processing observed in our study. However, more research is needed to confirm this with evidence, as data regarding participants' screen time and outdoor activity before and after the lockdown were not collected in this study.

There were several limitations to this study. First, our final sample size was small due to difficulties with recruitment during the early stages of reopening and fears of COVID-19 infection among participants. This was also contributed to by significant data loss due to signal contamination. Nevertheless, our sample size was comparable with other similar fNIRS studies $[8,51,52]$. Secondly, due to device specificity, we focused only on the frontal and occipital cortices, and were not able to assess deeper neuroanatomical structures [39]. Moreover, we did not control for participants' individual emotional relationship with the viewed spaces, such as level of familiarity or life events occurring in these spaces between $\mathrm{T} 1$ and T2, which may have potentially influenced the brain's response.

\section{Conclusions}

This study explored the impact of the COVID-19-related lockdown on changes in brain hemodynamics in response to three urban scenes. We found significant changes in the brain's reactivity to the visual stimuli, potentially linked to the lower mood and more depressive symptoms. Moreover, reduced cognitive functions developed over the lockdown can be attributed to a considerable change in daily routines during prolonged stay-at-home orders (for example, limited physical activity and increased screen time). These symptoms may lead to a heightened risk of mood and cognitive dysfunctions in confined populations. Furthermore, our study highlights the risk of increased psychological strain post-COVID-19 during exposure to typical busy urban street views, and the contrasting importance of green urban space exposure, which could counteract the negative effect of that strain, while also having further beneficial impact on the brain. 
Author Contributions: Conceptualization, A.O.-G.; methodology, A.O.-G. and S.F.H.; software, A.M. and S.N.; validation, A.O.-G., S.F.H. and A.M.; formal analysis, S.N.; investigation, A.O.-G.; resources, R.H., I.D. and C.S.H.; data curation, A.M. and S.N.; writing-original draft preparation, A.O.-G., writing-review and editing, A.O.-G., S.F.H., A.M., S.N. and I.D.; visualization, A.O.-G., A.M. and S.N.; supervision, R.H. and I.D.; project administration, R.H.; funding acquisition, R.H. and C.S.H. All authors have read and agreed to the published version of the manuscript.

Funding: This study was funded by NUS iHeathtech Other Operating Expenses (R-722-000-004-731) and NUS Department of Psychological Medicine Other Operating Expenses (R-177-000-003-001).

Institutional Review Board Statement: The study was conducted according to the guidelines of the Declaration of Helsinki, and approved by the Institutional Review Board of the National University of Singapore (protocol codes: NUS IRB\#:S-18-352 approved on 29 January 2019 and NUS IRB\#:S-20-126 approved on 20 May 2020).

Informed Consent Statement: Informed consent was obtained from all subjects involved in the study.

Data Availability Statement: Exclude this statement.

Acknowledgments: Authors want to thank all participants who agreed to voluntarily participate in the study despite the limitations related to COVID-19 restrictions, and to Raul Guizzo for proofreading.

Conflicts of Interest: The authors declare no conflict of interest.

\section{References}

1. Pasion, R.; Paiva, T.O.; Fernandes, C.; Barbosa, F. The AGE effect on protective behaviors during the COVID-19 outbreak: Sociodemographic, perceptions and psychological accounts. Front. Psychol. 2020, 11, 2785. [CrossRef] [PubMed]

2. Ammar, A.; Chtourou, H.; Boukhris, O.; Trabelsi, K.; Masmoudi, L.; Brach, M.; Bouaziz, B.; Bentlage, E.; How, D.; Ahmed, M. Covid-19 home confinement negatively impacts social participation and life satisfaction: A worldwide multicenter study. Int. J. Environ. Res. Public Health 2020, 17, 6237. [CrossRef]

3. Flanagan, E.W.; Beyl, R.A.; Fearnbach, S.N.; Altazan, A.D.; Martin, C.K.; Redman, L.M. The impact of COVID-19 stay-at-home orders on health behaviors in adults. Obesity 2021, 29, 438-445. [CrossRef] [PubMed]

4. Alirol, E.; Getaz, L.; Stoll, B.; Chappuis, F.; Loutan, L. Urbanisation and infectious diseases in a globalised world. Lancet Infect. Dis. 2011, 11, 131-141. [CrossRef]

5. Lai, C.Y.Y.; Ho, C.S.H.; Lim, C.R.; Ho, R.C.M. Functional near-infrared spectroscopy in psychiatry. BJPsych Adv. 2017, 23, 324-330. [CrossRef]

6. Scholkmann, F.; Kleiser, S.; Metz, A.J.; Zimmermann, R.; Pavia, J.M.; Wolf, U.; Wolf, M. A review on continuous wave functional near-infrared spectroscopy and imaging instrumentation and methodology. Neuroimage 2014, 85, 6-27. [CrossRef]

7. Ho, C.S.H.; Lim, L.J.H.; Lim, A.Q.; Chan, N.H.C.; Tan, R.S.; Lee, S.H.; Ho, R. Diagnostic and predictive applications of functional near-infrared spectroscopy for major depressive disorder: A systematic review. Front. Psychiatry 2020, 11, 378. [CrossRef]

8. Khoe, H.C.H.; Low, J.W.; Wijerathne, S.; Ann, L.S.; Salgaonkar, H.; Lomanto, D.; Choi, J.; Baek, J.; Tam, W.W.; Pei, H.; et al. Use of prefrontal cortex activity as a measure of learning curve in surgical novices: Results of a single blind randomised controlled trial. Surg. Endosc. 2020, 34, 5604-5615. [CrossRef]

9. Mangun, G.R.; Hopfinger, J.B.; Kussmaul, C.L.; Fletcher, E.M.; Heinze, H.J. Covariations in ERP and PET measures of spatial selective attention in human extrastriate visual cortex. Hum. Brain Mapp. 1997, 5, 273-279. [CrossRef]

10. Heinze, H.J.; Mangun, G.R.; Burchert, W.; Hinrichs, H.; Scholz, M.; Münte, T.F.; Gös, A.; Scherg, M.; Johannes, S.; Hundeshagen, H.; et al. Combined spatial and temporal imaging of brain activity during visual selective attention in humans. Nature 1994, 372, 543-546. [CrossRef]

11. Bratman, G.N.; Hamilton, J.P.; Daily, G.C. The impacts of nature experience on human cognitive function and mental health. Ann. N. Y. Acad. Sci. 2012, 1249, 118-136. [CrossRef]

12. Herman, K.; Ciechanowski, L.; Przegalińska, A. Emotional well-being in urban wilderness: Assessing states of calmness and alertness in informal green spaces (IGSs) with muse-Portable EEG headband. Sustainability 2021, 13, 2212. [CrossRef]

13. Lee, J. Experimental study on the health benefits of garden landscape. Int. J. Environ. Res. Public Health 2017, 14, 829. [CrossRef] [PubMed]

14. Olszewska-Guizzo, A.; Sia, A.; Fogel, A.; Ho, R. Can exposure to certain urban green spaces trigger frontal alpha asymmetry in the brain?-Preliminary findings from a passive task EEG study. Int. J. Environ. Res. Public Health 2020, 17, 394. [CrossRef] [PubMed]

15. Hartig, T.; Mang, M.; Evans, G.W. Restorative effects of natural environment experiences. Environ. Behav. 1991, 23, 3-26. [CrossRef]

16. Berman, M.G.; Jonides, J.; Kaplan, S. The cognitive benefits of interacting with nature. Psychol. Sci. 2008, 19, 1207-1212. [CrossRef]

17. Kaplan, S. Meditation, restoration, and the management of mental fatigue. Environ. Behav. 2001, 33, 480-506. [CrossRef] 
18. Olszewska-Guizzo, A.; Fogel, A.; Escoffier, N.; Ho, R. Effects of COVID-19-related stay-at-home order on neuropsychophysiological response to urban spaces: Beneficial role of exposure to nature? J. Environ. Psychol. 2021, 75, 101590. [CrossRef]

19. Moh Steps up Precautionary Measures in Response to Increase in Cases of Novel Coronavirus Pneumonia in Wuhan. Available online: https:/ / www.moh.gov.sg/news-highlights/details/moh-steps-up-precautionary-measures-in-response-to-increasein-cases-of-novel-coronavirus-pneumonia-in-wuhan (accessed on 6 May 2020).

20. Hart, B.M.; Schmidt, H.C.E.F.; Klein-Harmeyer, I.; Einhäuser, W. Attention in natural scenes: Contrast affects rapid visual processing and fixations alike. Philos. Trans. R. Soc. Lond. B Biol. Sci. 2013, 368, 20130067. [CrossRef]

21. Tsuzuki, D.; Jurcak, V.; Singh, A.K.; Okamoto, M.; Watanabe, E.; Dan, I. Virtual spatial registration of stand-alone fNIRS data to MNI space. NeuroImage 2007, 34, 1506-1518. [CrossRef]

22. Tsuzuki, D.; Cai, D.S.; Dan, H.; Kyutoku, Y.; Fujita, A.; Watanabe, E.; Dan, I. Stable and convenient spatial registration of stand-alone NIRS data through anchor-based probabilistic registration. Neurosci. Res. 2012, 72, 163-171. [CrossRef]

23. Tsuzuki, D.; Dan, I. Spatial registration for functional near-infrared spectroscopy: From channel position on the scalp to cortical location in individual and group analyses. NeuroImage 2014, 85, 92-103. [CrossRef] [PubMed]

24. Rorden, C.; Brett, M. Stereotaxic display of brain lesions. Behav. Neurol. 2000, 12, 191-200. [CrossRef] [PubMed]

25. Huppert, T.J.; Diamond, S.G.; Franceschini, M.A.; Boas, D.A. HomER: A review of time-series analysis methods for near-infrared spectroscopy of the brain. Appl. Opt. 2009, 48, D280-298. [CrossRef]

26. Uga, M.; Dan, I.; Sano, T.; Dan, H.; Watanabe, E. Optimizing the general linear model for functional near-infrared spectroscopy: An adaptive hemodynamic response function approach. Neurophotonics 2014, 1, 015004. [CrossRef]

27. Hoshi, Y.; Kobayashi, N.; Tamura, M. Interpretation of near-infrared spectroscopy signals: A study with a newly developed perfused rat brain model. J. Appl. Physiol. 2001, 90, 1657-1662. [CrossRef]

28. Strangman, G.; Culver, J.P.; Thompson, J.H.; Boas, D.A. A quantitative comparison of simultaneous BOLD fMRI and NIRS recordings during functional brain activation. NeuroImage 2002, 17, 719-731. [CrossRef] [PubMed]

29. Hoshi, Y. Functional near-infrared optical imaging: Utility and limitations in human brain mapping. Psychophysiology 2003, 40, 511-520. [CrossRef] [PubMed]

30. Plichta, M.M.; Herrmann, M.J.; Baehne, C.G.; Ehlis, A.C.; Richter, M.M.; Pauli, P.; Fallgatter, A.J. Event-related functional near-infrared spectroscopy (fNIRS): Are the measurements reliable? NeuroImage 2006, 31, 116-124. [CrossRef]

31. Jang, K.E.; Tak, S.; Jung, J.; Jang, J.; Jeong, Y.; Ye, J.C. Wavelet minimum description length detrending for near-infrared spectroscopy. J. Biomed. Opt. 2009, 14, 034004. [CrossRef] [PubMed]

32. Friston, K.J.; Fletcher, P.; Josephs, O.; Holmes, A.; Rugg, M.D.; Turner, R. Event-related fMRI: Characterizing differential responses. NeuroImage 1998, 7, 30-40. [CrossRef]

33. Uga, M.; Dan, I.; Dan, H.; Kyutoku, Y.; Taguchi, Y.H.; Watanabe, E. Exploring effective multiplicity in multichannel functional near-infrared spectroscopy using eigenvalues of correlation matrices. Neurophotonics 2015, 2, 015002. [CrossRef]

34. American Psychological Association. Publication Manual of the American Psychological Association; APA: Washington DC, USA, 1994.

35. Olsson-Collentine, A.; Van Assen, M.A.L.M.; Hartgerink, C.H.J. The prevalence of marginally significant results in psychology over time. Psychol. Sci. 2019, 30, 576-586. [CrossRef]

36. Fink, G.R.; Marshall, J.C.; Halligan, P.W.; Frith, C.D.; Frackowiak, R.S.J.; Dolan, R.J. Hemispheric specialization for global and local processing: The effect of stimulus category. In Proceedings of the Royal Society B: Biological Sciences; The Royal Society: London, UK, 1997; Volume 264, pp. 487-494.

37. Olszewska-Guizzo, A.A.; Paiva, T.O.; Barbosa, F. Effects of 3D contemplative landscape videos on brain activity in a passive exposure EEG experiment. Front. Psychiatry 2018, 9, 317. [CrossRef]

38. Wang, C.; Chudzicka-Czupała, A.; Grabowski, D.; Pan, R.; Adamus, K.; Wan, X.; Hetnał, M.; Tan, Y.; Olszewska-Guizzo, A.; Xu, L. The association between physical and mental health and face mask use during the COVID-19 pandemic: A comparison of two countries with different views and practices. Front. Psychiatry 2020, 11, 901. [CrossRef]

39. Husain, S.F.; Yu, R.; Tang, T.-B.; Tam, W.W.; Tran, B.; Quek, T.T.; Hwang, S.-H.; Chang, C.W.; Ho, C.S.; Ho, R.C. Validating a functional near-infrared spectroscopy diagnostic paradigm for major depressive disorder. Sci. Rep. 2020, 10, 1-9. [CrossRef]

40. Ward, L.M.; Aitchison, R.T.; Tawse, M.; Simmers, A.J.; Shahani, U. Reduced haemodynamic response in the ageing visual cortex measured by absolute fNIRS. PLoS ONE 2015, 10, e0125012. [CrossRef] [PubMed]

41. Bakker, S.L.M.; de Leeuw, F.-E.; den Heijer, T.; Koudstaal, P.J.; Hofman, A.; Breteler, M.M.B. Cerebral haemodynamics in the elderly: The rotterdam study. Neuroepidemiology 2004, 23, 178-184. [CrossRef] [PubMed]

42. Duric, V.; Duman, R.S. Depression and treatment response: Dynamic interplay of signaling pathways and altered neural processes. Cell. Mol. Life Sci. 2013, 70, 39-53. [CrossRef]

43. Davidson, R.J.; Ekman, P.; Saron, C.D.; Senulis, J.A.; Friesen, W.V. Approach-withdrawal and cerebral asymmetry: Emotional expression and brain physiology: I. J. Personal. Soc. Psychol. 1990, 58, 330. [CrossRef]

44. Hofer, S.M.; Berg, S.; Era, P. Evaluating the interdependence of aging-related changes in visual and auditory acuity, balance, and cognitive functioning. Psychol. Aging 2003, 18, 285. [CrossRef]

45. Schmidt, S.C.E.; Anedda, B.; Burchartz, A.; Eichsteller, A.; Kolb, S.; Nigg, C.; Niessner, C.; Oriwol, D.; Worth, A.; Woll, A. Physical activity and screen time of children and adolescents before and during the COVID-19 lockdown in Germany: A natural experiment. Sci. Rep. 2020, 10, 1-12. [CrossRef] 
46. Wong, C.W.; Tsai, A.; Jonas, J.B.; Ohno-Matsui, K.; Chen, J.; Ang, M.; Ting, D.S.W. Digital screen time during the COVID-19 pandemic: Risk for a further myopia boom? Am. J. Ophthalmol. 2021, 223, 333. [CrossRef] [PubMed]

47. Castañeda-Babarro, A.; Arbillaga-Etxarri, A.; Gutiérrez-Santamaría, B.; Coca, A. Physical activity change during COVID-19 confinement. Int. J. Environ. Res. Public Health 2020, 17, 6878. [CrossRef] [PubMed]

48. Bourdas, D.I.; Zacharakis, E.D. Evolution of changes in physical activity over lockdown time: Physical activity datasets of four independent adult sample groups corresponding to each of the last four of the six COVID-19 lockdown weeks in Greece. Data Brief 2020, 32, 106301. [CrossRef]

49. Iwasaki, T.; Tawara, A.; Miyake, N. Reduction of asthenopia related to accommodative relaxation by means of far point stimuli. Acta Ophthalmol. Scand. 2005, 83, 81-88. [CrossRef]

50. Reddy, S.C.; Low, C.K.; Lim, Y.P.; Low, L.L.; Mardina, F.; Nursaleha, M.P. Computer vision syndrome: A study of knowledge and practices in university students. Nepal. J. Ophthalmol. 2013, 5, 161-168. [CrossRef]

51. Joung, D.; Kim, G.; Choi, Y.; Lim, H.; Park, S.; Woo, J.-M.; Park, B.-J. The prefrontal cortex activity and psychological effects of viewing forest landscapes in autumn season. Int. J. Environ. Res. Public Health 2015, 12, 7235-7243. [CrossRef] [PubMed]

52. Kassab, A.; Le Lan, J.; Tremblay, J.; Vannasing, P.; Dehbozorgi, M.; Pouliot, P.; Gallagher, A.; Lesage, F.; Sawan, M.; Nguyen, D.K. Multichannel wearable f NIRS-EEG system for long-term clinical monitoring. Hum. Brain Mapp. 2018, 39, 7-23. [CrossRef] 